\title{
THE ROLE OF IDENTITY IN SHAPING RESILIENT OPEN PUBLIC SPACES SURROUNDING SMALL URBAN STREAMS
}

\author{
DOI: 10.18485/arh_pt.2020.7.ch11
}

\author{
Aleksandra Djukić \\ Associate Professor, Ph.D, University of Belgrade, Faculty of Architecture, \\ Bulevar kralja Aleksandra 73/II, adjukic@afrodita.rcub.bg.ac.rs \\ - Višnja Sretović Brković \\ Research Assistant, University of Belgrade, Faculty of Architecture, \\ Bulevar kralja Aleksandra 73/II, visnja_sretovic@yahoo.com
}

\section{ABSTRACT}

Open public spaces surrounding small urban streams are faced with a growing number of problems in the last few decades as a result of climate change. Frequent floods and droughts made most of these areas non-functional, abandoned and devastated for the better part of the year. Majority of the spaces surrounding small urban streams currently are not capable to adapt and transform in accordance with new ecological challenges.

In order to create public spaces that live year-round, it is necessary to design them according to principles of resilient design. The socio-ecological resilience, an interdisciplinary concept based in ecology, offers a conceptual ground for the principles for creation of resilient spaces, i.e. spaces that are resilient to the changes and utilize natural disturbances for the improvement of space. According to this concept, one of the most important qualities of resilience is preservation of identity in times of natural disturbances and recovery.

In this paper we will analyse the question of identity of open public spaces surrounding small urban streams in the context of resilience, based on the case of watercourses in Belgrade. The goal of this research is to identify the elements that shape the identity of open public spaces and to determine their role in the future revitalization of these spaces, in order to realize year-round uniform quality of space.

KEYWORDS _ small urban streams, public open spaces, resilience, identity

\section{INTRODUCTION}

In recent decades, small water streams in cities have experienced changes that have been intensified under the influence of uncontrolled urban development and climate change. The water level is becoming increasingly unpredictable, floods and droughts are getting more common as well as high levels of pollution and erosion. All of this leads to exclusion of these zones from city life and their perception as a problem. However, these spaces do not have to be eliminated from the urban activity system and they have potential for improving urban quality in social, aesthetic, economic, and functional terms. To become a functional part of the city, it is necessary to maintain a consistent quality of space during all periods of gradual or sudden changes and disturbances.

Recognizing the value of small urban streams in cities, urban design plays an important role as the essential carrier of potential for their sustainability, resilience, and the increase of their capacity 
as functional green open spaces. For urban design to respond to the revitalization of small urban streams, it is essential to formulate its principles under the umbrella of the concept of socio-ecological resilience, as well as to comply with local and specific requirements of small streams in an urban area. Urban resilience to floods lies in a principle that instead of fighting the river, cities live with periodic floods and allow them to enter the city (Liao, 2012). That brings major changes to urban design, as it now strives for a space that will constantly adapt and transform under the influence of the disturbances while living and functioning for the duration of the change and recovery period at the same time.

The framework of predictability and ready-made solutions used in urban design must be modified and expanded with new knowledge regarding the inability to control change. This calls for a rethinking of the different aspects on which urban design has been based on so far, and modification of some of those aspects. One of these is identity. This is especially important element in urban design and represents a significant part of the concept of socio-ecological resilience. In this text, we will address the issue of the identity of open public spaces on the banks of small urban streams and their position in the context of creating a resilient space, and we will analyse what elements of space make up its identity.

\section{IDENTITY WITHIN THE SOCIO-ECOLOGICAL RESILIENCE CONCEPT}

Within the socio-ecological resilience concept, identity has an important role in affecting the resilience. Walker and Mayers state in their often-cited definition that "socio-ecological resilience is defined as the capacity of a system to absorb disturbance and to reorganize on its own for the duration of the change caused by a disturbance while maintaining the basic function, structure, feedback, and identity" (Walker and Meyers, 2004). Identity is, for the most part, constant, which means that its basic structure remains invariable, despite changes which may occur. However, as it depends on society - that is constantly changing in line with standards, expectations, and values - the question is whether the identity is truly invariable (Gersonius et al., 2012).

Some authors even consider identity as the most important indicator of resilience of a given system. If the resilience of a system is low, identity is lost, or vice versa, if identity is lost, the system resilience is considered low. Resilience becomes equal to the maintenance and restoration of key components and connections and their continuous duration over time and can be measured by quantifying identity and assessing threats which indicate that change in identity will take place (Cumming, 2011).

In conclusion, given the importance of identity for the creation of resilient spaces, it must be considered from the urban design perspective as well.

Within the field of urban design, the place identity is considered significant because man links a part of his own self to a place. Every environment has features which make it different than others and help establish its unique identity (White, 1996). However, understanding and defining the elements that make up its identity is an open issue and requires further research. Kevin Lynch believes that the way a certain space feels varies, and it depends on the person observing, their skills to observe and differentiate spaces and forms, and that city spaces have a multifaceted meaning since they are viewed and used by multiple individuals. This type of approach makes identifying elements of identity more difficult (Đukić, 2011).

In order to apply the concept of identity from the socio-ecological resilience to the field of urban design, namely the design of open public spaces on the banks of small urban water streams, further study is needed to determine which elements of this concept are applicable to place identity and under which conditions. 


\section{THE CHARACTERISTICS OF OPEN PUBLIC SPACES ON THE BANKS OF SMALL URBAN STREAMS AS A FUNCTION OF IDENTITY}

Open public spaces on the banks of small streams need to be designed as resilient, due to the continuous and abrupt changes which they are faced with, which also threaten them. The concept of socio-ecological resilience offers a response to those changes.

Open public spaces on the banks of small urban streams represent a special category of open public spaces in cities. They contain several similarities to other urban spaces of this type, but also some specifics that make them unique. The characteristics of resilient open public spaces on the banks of small urban streams, which impact the formation of identity will be outlined below.

\section{Integrity and segmentation of small urban stream shorelines}

The first significant question in the approach to the revitalization of open public spaces along the small urban streams is how are the banks viewed and perceived: as a whole or segmented? The length of small water streams in the city area ranges from several kilometres to several tens of kilometres, so the area is difficult to experience as a whole. In addition, the physical, functional, and cultural diversity of the spaces through which the streams flow makes it difficult to view and generalize patterns as a whole. Urban spaces are most often experienced through a series of images alternating as they move (Đukić, 2011).

On the other hand, the elements which tie these spaces together, such as water, shoreline, pedestrian and/or bike baths, are what the entire shoreline has in common with the city zone, and what ties that space into one entity, creating the continuity of space. The recognition of this type of open public space in relation to others in the surrounding area gives it a sense of integrity. From that, it is safe to conclude that identity needs to be looked at from two angles, as a whole - the bank areas of small urban streams and as individual open public spaces.

The representation of the identity elements which make up the whole should be so large as to ensure the continuity of space, but on the other hand not too large, to avoid the monotony of the same. Large, monotonous spaces lose their identity (Đukić, 2011). Therefore, it is very important to work on the diversity of identities of individual open spaces. Categorization of space is necessary to bring clarity to the experience of space.

\section{Spatial diversity}

Considering that they run through different parts of the city, open public spaces along the banks can significantly differ from one another. Their shaping is conditioned by the physical, functional, and cultural qualities of the urban zones through which they pass. The distance from the city centre also affects their design. The areas outside the central zone are generally large, rich in greenery and various contents, while ones in central zones are narrow stretches along river streams. The rhythm of the elements in a space is also conditioned by the position in the city. Where pedestrian movement is dominant, the rhythm should be more subtle compared to parts of the city where other forms of movement are dominant (Đukić, 2011).

The appearance of water and the way the stream is regulated influences the approach to the design. Linear flow dictates a different way of shaping open public spaces, compared to retentions. Spaces created along the concrete lined channels will completely differ than those created along the streams that use natural landscaping. Combining different types of river regulations and appearance of water through different urban zones and incorporating many activities creates a dynamic space.

\section{Prevalence of green spaces within a public space}

Open public spaces on the banks of small urban streams have even more pronounced features of socio-ecological systems on which the concept of socio-ecological resilience is based, than any other city structure. They are a union between nature and man, a union of the built and the unbuilt. Natural processes are, to a great extent, what determines how these spaces are shaped (McHarg, 1996). 
The share of green spaces increases, when the design of the small watercourses is based on the natural landscaping. This approach is possible within urban zones where spatial capacities are in place and where such spaces can be integrated into existing surroundings. The safety and educational element of the space that uses natural landscaping systems are essential to their functions. Safety is viewed in the context of traffic, prevention of crime, and unpleasant climate factors. The educational function is about spreading awareness of the importance of nature through the involvement of the community.

\section{The unbreakable bond between banks and water}

In large and wide rivers, water is the dominant element, while the banks are faraway, making their identities quite independent and spatially detached. On the other hand, small urban streams represent a visually and functionally inseparable whole with open spaces that surround them. They need to be seen integrally, as a single unit of open public space and water, defined in a broader context, as physical and social space, saturated with all the complexities of the context in which it is located.

\section{Variability of water appearance in open public spaces}

As previously mentioned, the banks and the water are an inseparable whole. However, the ratio of the representation of these elements changes significantly, depending on the cyclical and abrupt changes which small water streams face. The consequences of the changes are the alteration between periods of low and high-water levels, floods, and drought.

Depending on these circumstances, the ratio of the representation of water and dry parts in space also changes. When the stream dries, the connection between the banks is even more pronounced, and the space is given completely new features and with that, a new identity. With extremely high-water levels and floods, the water dominates and occupies much of the open public space. Because of this variability, the question arises: during the design, what should the focus be on? The open public space with elements of water, or is the water surface dominant, along with its influence on the surrounding space.

\section{Activities within a space}

When spaces are high-quality, there are many actives from which the users can choose from, as well as a whole number of social activities that can pop up spontaneously as long as there is a presence of people (Gehl, 2010). Considering that the design of a space is viewed thought the physical aspect as well as though the behaviour and activities of people, it is very complicated to coordinate the urban form and existing patterns of human activity in space and time (Lynch, 1972). The structure of activity in public spaces is affected by the design and shaping of the physical environment, while at the same time, the space stimulates the activities that are to take place in that environment.

Combinations of different types of activities are required to create resilient open spaces. Activities occurring in a space must be synchronized over time. Conflicts between activities competing at the same time need to be reconciled (Lynch, 1972). Human-rich urban spaces allow for complementary activities that overlap in space and are complexly interconnected (Carmona, et al., 2003). Understanding the patterns of activity in space and time makes it possible to achieve the synergy of activities in one space and improves the quality of space.

\section{THE EXAMPLE OF SMALL URBAN STREAMS IN BELGRADE}

Belgrade lies on a complex network of small urban streams, which are concentrated on the right banks of the Sava and Danube rivers. There used to be more of these streams, and they played a key role in the urban life of the city. That is how, for example, the Topčider River, one of Belgrade's largest streams, was used as a beach, which was connected to the hot spring baths which were once part of the Topčider Park (Ćorovic and Blagojević, 2012). 

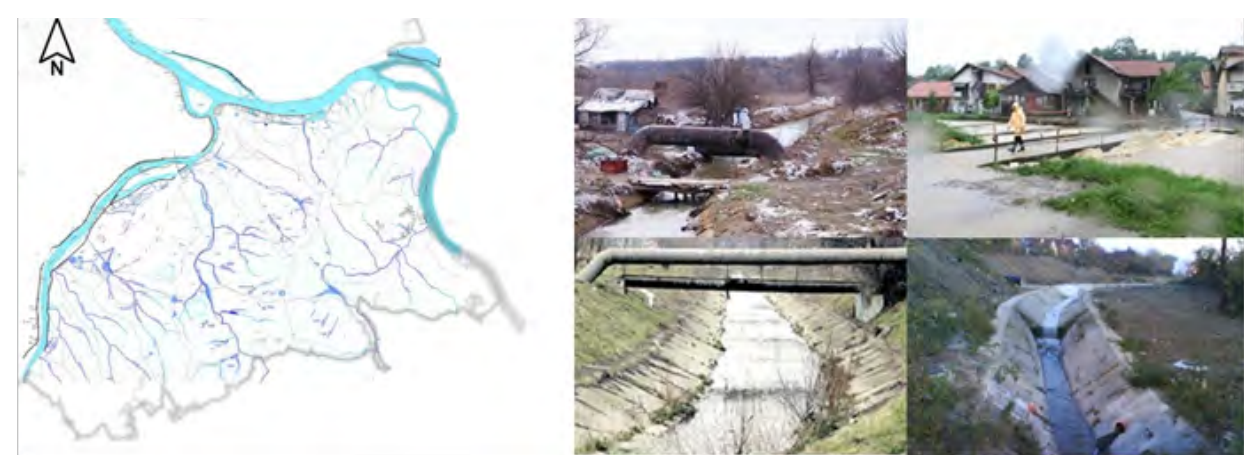

_ Figure 1: Small urban streams and rivers in Belgrade (Image sources: 1) Master Plan of Belgrade 2021

2) own work, 3) www.blic.rs, 4) L.Vuletić (V.V., 2008), 5) www.beobuild.rs

In the twentieth century, small urban streams lost their role in the development of the city and began to be seen as a problem. Their value becomes insignificant in the rush of mass construction. Many of them are piped and removed from the urban landscape. Some have been preserved (regulated or not), however completely cut off from city life. Additionally, their waters are highly polluted and cause major flooding in the city.

According to the General Regulation Plan of the System of Green Spaces in Belgrade, a green urban network is planned, as well as green corridors on which recreation is planned. One of the priorities is the preservation of the natural valleys of small water streams, and their regeneration. The tendency is to use natural regulation of the stream bed with the necessary biotechnical measures in the catchment area.

Taking into consideration the planned revitalization of Belgrade's streams, it is necessary to understand whether there is an awareness among the citizens of stream's identity and whether it's possible to identify which elements making the identity of the streams should be preserved following the revitalization. The question is whether, after many years of exclusion of streams from city life, citizens recognize some patterns that need to be preserved, that is, whether there are memories that have a longer life span than the space itself. Early recognition of the identity elements of existing and future spaces, present in the minds of citizens, is important for maintaining identity in the process of creating and using resilient open public spaces along the banks of small streams.

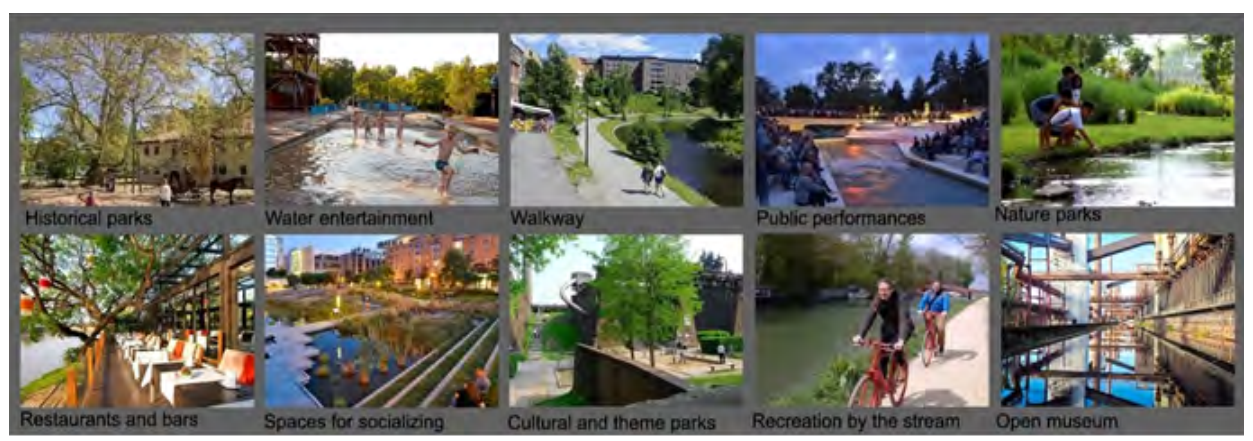

_ Figure 2: Different types of landscape and activities (Images sources: Historical park- https://bit.ly/3gDw60J; Water entertainment - https://bit.ly/3gJFX5t; Walkway - https://bit.ly/2XoUoEE; Public performances - https://bit.ly/3cl1XjT; Nature parks - Photo by Atelier Dreiseitl https://bit.ly/3eGk8lv; Restaurants and bars - https://bit.ly/2Mm4akg; Social spaces - https://bit.ly/2ySu5Nq; Cultural and theme parks - https://bit.ly/2MjLt0D; Recreation by the stream - https://bit.ly/2AxxZvv; Open museum -https:// bit.ly/2Mi8HEj) 
In order to determine the level of awareness of the identity of streams, and analyse the way the citizens perceive them and wish them to look like and be used following the revitalization, we conducted an online pilot survey involving 117 respondents. All were legal adults (over 18 years of age) and have been residing or staying in Belgrade for a long period of time. They were presented with multiple choice questions about potential appearance of the small urban streams in Belgrade, accompanied by photographs showing different types of landscape and activities with brief descriptions. The selection was created in such way to offer diverse combinations of river regulations and pursuits that could be organized there (Figure 2). The questions address each of the identity-relevant characteristics of the spaces, as defined in the previous chapter.

Integrity and segmentation of space. One of the goals of the survey was to find out if citizens perceive the streams as a whole, or if they assign importance to only segments of it. Majority of the citizens believe that the condition in which the streams are is very bad and that very few elements need to be preserved. This is confirmed by the answer to the question in which the respondents were asked to assess the appearance of streams on a scale from 1 to 5 , one being "unsatisfactory" to five being "nicely landscaped streams" and their general impressions of them. The highest percentage of respondents ( $47.8 \%$ ) feel that the appearance of the streams is unsatisfactory. Only $9.7 \%$ consider their appearance to be average, while none of the respondents rated the streams satisfactory or nicely designed (Đukić and Sretović Brković, 2018).

The current condition of the streams is estimated by citizens to be very poor and they do not recognize the elements that need to be preserved, but they perceive all streams as a whole. When selecting activities which they would like to take place at these streams after revitalization, they generally chose those activities that extend along the entire shore: most of the respondents (93.2\%) selected nature parks. Recreation by the stream was in second place, selected by $70.9 \%$ of the respondents. In third place was a walkway, selected by $68.4 \%$ of the respondents.

On the other hand, citizens have identified zones that differ in their distinctiveness, and there is a completely different attitude to them when it comes to preserving their identities. Of the total number of respondents, $85.5 \%$ of the respondents had heard about Topčider River. It is one of the largest small urban streams in Belgrade. It can be visited only in part that passes through the eponymous Topčider Park, which has great natural, historical, and cultural value, as part of the identity of the entire city. $50.4 \%$ of the surveyed citizens believe that the preservation of cultural heritage in the valley of Belgrade streams is significant, which is mostly related to this park.

The diversity of open public spaces. The second part of the survey focused on gaining insight into the diversity of the space. To get more information about the potential future look of the streams and the surrounding areas, we presented the respondents with photos illustrating various landscaping solutions: (2) concrete stream channelization, (3) natural channel design, (4) a mixture of natural and concrete design and (1) an option of piping a stream and using a land above. We asked them to choose an option they consider the most attractive. It is important to emphasize that this question dealt only with the appearance of streams. It was interesting that none of the respondents opted for piping a stream and using a land above for the development, and only $1.71 \%$ of respondents opted for concrete stream embankments that are the most common way of regulating small rivers in Serbia. Out of the $98.29 \%$ of users that choose more sustainable and resilient options, $86.32 \%$ of them opted for the diverse look of stream banks - a mixture of natural channel design and stream channelization. According to the results, we concluded that the citizens would like the streams in their environment to be visible and that most of the survey participants prefer the diverse look of stream banks (Figure 3).

When it comes to diversity of the activities which the survey participants would like to follow the revitalization, they mostly chose activities which they were already accustomed to: spending time in nature, riding bikes, walking, and socializing. Only a small portion of the respondents opted for activities such as public gathering, performances, and open-air concerts, swimming, and water entertainment. Based on that, it is concluded that they aren't very interested in a large number of activities, and instead, they opt for the activities which they are used to, or that are tied to existing green spaces within the city. 

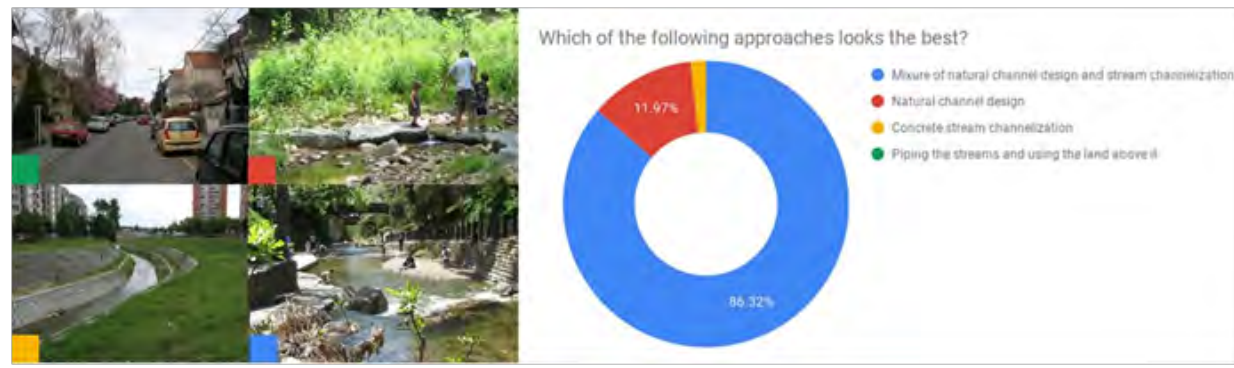

_Figure 3: Responses on the question: "Which of the following approaches looks the best?" (Image sources: https:// www.herndon-va.gov/departments/stormwater-management and https://cartas.typepad.com/main/2011/04/ downtown-san-luis-obispo.html)

Great representation of green spaces within open public spaces. Throughout this survey, it is concluded that there is a clear majority stance regarding green spaces. One of the main conclusions of this study is that citizens want to reduce the pollution on small streams and enable a return to the natural surroundings with their revitalization. Almost all of them surveyed, $97.3 \%$ indicated that large quantities of waste along the shoreline as well as water pollution were considered the biggest problem. When asked about the future desired appearance and purpose of open public spaces along the shoreline, most of the respondents, as many as $92.9 \%$ opted for nature parks.

An unbreakable link between the river and the bank. An important issue for understanding identity is how citizens perceive the connections between open public space and water, especially their relationship to water in a space. Respondents consider water an important element, which has a decorative role and serves only to create a pleasant environment.

The multifunctional use of water or its integration into other parts of the space was not widely accepted by the respondents. Although these streams have been used for swimming and leisure in the past, such perception of the streams has not been retained. When interviewing several older respondents who recalled the time when the streams were used for bathing, all responded that they would not want the streams to be used for this purpose after revitalization, since they remember stories of their danger, as well as the drowning of several children. This was confirmed by the response of all respondents: less than $15 \%$ of citizens opted for one of the suggested methods of interactive water use.

Variety of water forms in the relation between river and banks. Citizens were not asked about the changes of the streams since the revitalization in the function of resilience has not been carried out. Activities within a space. As mentioned, the current condition of the streams is deemed unsatisfactory by most respondents. The pollution and the quantity of waste are recognized as the largest problem by the majority of the respondents $(97.3 \%$ ) while inaccessibly to streams, that was listed by $57.76 \%$ of the respondents, was recognized as a significant issue. That has led to a small number of activities that can currently be observed in these open public spaces along the banks of small streams. The streams are poorly visited, apart from the well-known ones such as Topčider Park in which various activities are present and could be discussed.
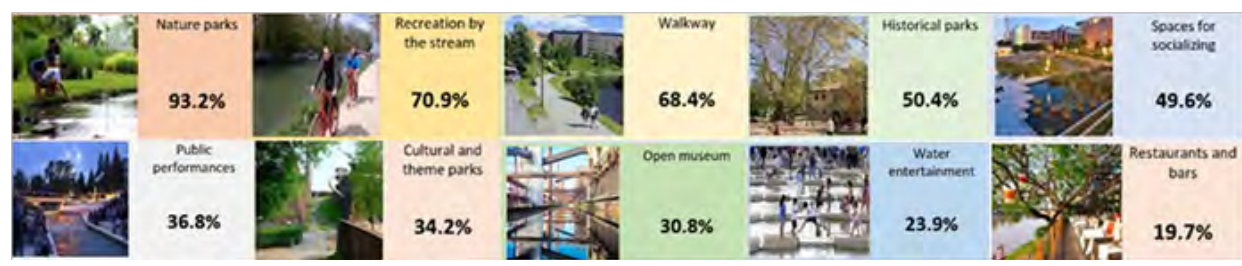

_ Figure 4: The preferred activities following the stream revitalization (Image sources: same as in the Figure 2) 
To get a clear representation of the preferred activities following the stream revitalization, the survey respondents were asked to select at most five of the photographs showing different landscape types with description of activities that may appear on the small rivers and streams. The results show that citizens prefer open public spaces along the shorelines and spending time in nature, recreation, walking, and socializing. Things of historical value were also quite important to the respondents. Theatres, concerts in the open, and or conversion of brownfields into cultural or theme parks did not prove to be of interest to them. Finally, swimming and water entertainment were chosen by the smallest number of respondents (Figure 4). It is interesting to note that only $19.5 \%$ opted for restaurants and bars, which are otherwise very popular in Belgrade. Whether there is an oversaturation of such contents or they did not find them suitable for small urban streams cannot be deduced from the survey (Đukić and Sretović Brković, 2018).

\section{CONCLUSION}

The conducted research considers the planning stage of the small watercourse revitalization process. Given that existing spaces in Belgrade are not designed to be resilient, and that disturbances such as floods or droughts completely devastate space, it was not possible to investigate the variability or the stability of identity elements. This may be the subject of research during or after the streams' revitalization is completed. However, the step taken here is significant, as it identifies and narrows down the identity elements that the respondents consider important and which should be nurtured in further interventions on Belgrade's streams. It should be noted that the survey presented in this study was conducted on a small number of respondents (not all ages were included, and all streams were observed in general). As such, the results of this survey should be used as an input for organizing another survey on a more accurate sample, which would then provide more valid data on the citizens' opinion of streams.

The question of resilient spaces and their identity requires a great deal of further research that should more clearly define the position of social resilience within the concept of socio-ecological resilience. While the ecological segment of resilience is highly elaborated within the socio-ecological resilience framework, the social aspect requires further research which would verify the possibility of linking the social and eco-systems together and defining their relationship (Olsson et al.,2015). The issues of change and/or the stability of identity are still under-researched and require defining the basic elements of stability and/or change, or the formation of principles for determining them. Identity must have some variability due to the continuous changes in society: values, attitudes of citizens, etc. In the event of disturbances, spaces significantly change their character and function. After passing disturbances, the spaces renew their identity and try to restore it. However, throughout the disturbance and recovery periods which are not necessarily brief, a space acquires another identity that is also significant and becomes part of the citizen's consciousness. The question arises as to whether there is only one identity, or perhaps it is necessary to look at several different identities in one area (e.g. during floods, high water levels, low water levels, droughts) or whether it is that constant variability of a space forms its identity.

\section{REFERENCES}

_ Carmona, Matthew; Heath, Tim; Oc Taner and Steve Tiesdell. 2003. Public Places - Urban Spaces: The Dimensions of Urban Design. Oxford: Architectural Press.

_ Cumming, Graeme S. 2011. "Spatial resilience: integrating landscape ecology, resilience, and sustainability" Landscape Ecology, 26: 899-909

_ Ćorović, Dragana and Ljiljana Blagojević. 2012. "Water, Society and Urbanization in the 19th Century Belgrade: Lessons for Adaptation to the Climate Change." Spatium, no. 28: 53-59. 
- Đukić, Aleksandra. 2011. Očuvanje identiteta glavne ulice vojvođanskog grada u procesu urbane obnove. Doktorska disertacija. Beograd: Arhitektonski fakultet Univerziteta u Beogradu

_- Đukic, Aleksandra and Višnja Sretović Brković. 2018. "Raising Citizen Awareness through Promoting Benefits of Small Urban Streams Revitalization", Nis, 2nd International Conference on Urban Planning ICUP2018

_ Gehl, Jan. 2011. Life between Buildings: Using Public Space. Washington: Island Press.

- Gersonius, Berry; Ashley, Richard, and Chris Zevenbergen. 2012. "The identity approach for assessing socio-technical resilience to climate change: example of flood risk management for the Island of Dordrecht." Natural Hazards and Earth Systems Science, no.2: 2139-2146.

- Liao, Kuei - Hsien. 2012. "A Theory on Urban Resilience to Floods. A Basis for Alternative Planning Practise." Ecology and Society 17, no.4: 48 http://dx.doi.org/10.5751/ES-05231-170448

- Lynch, Kevin. 1972. What time is this place? Massachusetts: MIT Press Media Department

_ McHarg, Ian. 1996. "Nature in the Metropolis." In City Reader, edited by Richard T. LeGates and Frederic Stout, 132-141. New York: Routledge.

- Olsson, Lennart; Jerneck, Anne; Thoren, Henrik; Persson, Johannes and David O'Byrne. 2015. "Why resilience is unappealing to social science." Science Advances, no 1: $4 \mathrm{http}$ ://advances.sciencemag.org/ content/1/4/e1400217

- Walker, Brian, and Jacqeline Meyers. 2004. "Thresholds in ecological and social-ecological systems: a developing database." Ecology and Society, 2, no. 9

- White, William. 1996. "The Design of Space." In City Reader, edited by Richard T. LeGates and Frederic Stout, 109-117. New York: Routledge. 